\title{
Consumers' Different Attitudes towards Genetically Modified Food in the United States and China
}

\author{
Yue $\mathrm{Ma}^{1}$ \\ ${ }^{1}$ Graduate School of Chinese Academy of Social Science, Beijing, China \\ Correspondence: Yue Ma, Graduate School of Chinese Academy of Social Science, Fang Shan Distract, Beijing, \\ China. Tel: 86-183-1108-5605.E-mail: mayue_0105@126.com
}

Received: March 23, 2015 Accepted: April 20, 2015 Online Published: July 2, 2015

doi:10.5430/sass.v2n2p1 URL: http://dx.doi.org/10.5430/sass.v2n2p1

\begin{abstract}
Genetically modified food is a hot topic in the global. Consumers' attitudes have been studied for more than one decade in the United States, Europe, China and other countries. This paper provides an overview on the consumers' attitudes towards genetically modified food in the United States and China with the available data. The results show that consumers' attitudes towards genetically modified food are different in these two countries because of some reasons, such as perception risk, cultural tradition, government policy and so on. However, there are some common issues which consumers in the United States and China are all concerned with, such as, health risk, environmental risk, especially genetically modified food labeling. Thus, genetically modified food not only involves science and technology issues, but also ethical issues. Precautional principle and non-maleficence principle are two important moral rules for researchers and relevant firms in the production period of genetically modified food. In short, if consumers do not decide and control the production of genetically modified food, at least genetically modified food should be labeled. Because consumers have rights to know what they eat and to choose food freely in the market.
\end{abstract}

Keywords: Transgenic Technology, Genetically Modified Food, Genetically Modified Food Labeling, Perceived Risk, Ethic Issue, Precautional principle, Non-maleficence

\section{Introduction}

Since scientists discovered that DNA can transfer from one organism to another through special technological skills for the first time. Then, transgenic technology has got rapidly developed. In 1983, the first genetically modified plant possessing antibiotic-resistant tobacco was produced in America. Then, the transgenic Flavr Savr tomato was sanctioned by the FDA (Food and Drug Administration of America) for marketing in America in 1994. Some scientists optimistically claimed that desirable plant traits and animal traits could be selected, combined and propagated through this new transgenic technology. Transgenic technology not only makes evolutional procedures to be dramatically accelerated in a highly targeted manner by introducing new genes, but also crosses the barrier of sexual incompatibility between different species. Thus scientists predict that transgenic technology may be used in a number of ways, such as drought, extreme temperature or salinity, insects pathogens which would bring more welfare to human beings. For example, farmers and consumers would get more benefits because of transgenic tomato's trait of resisting pestis and longer maturation period in the production, which might reduce the use of amount of agricultural chemicals and damage in the transport procedures and engender huge social and economic benefits. Furthermore, advocates of this new biotechnology promise that genetically modified food will contain more nutritions and quality-enhanced food supply for consumers than traditional food.

In addition, scientists claim that transgenic technology is not only used in plant kingdom, but also in faunal kingdom. For example, scientists foster new species through transplanting DNA which own excellent heredity from one body to another in order to cultivate some new varieties. There are many news that scientist start to research transgenic modified animals after the victory of genetically modified crops. As a result, some scientists optimistically claim that transgenic technology not only increases the amount of food in the global, but also improves the nutritional content of the food and genetically modified foods are exceedingly beneficial to cure malnutrition in the developing countries. 
However, when genetically modified food appeared in human society, arguments concerning it have never stopped. In recent years, a series of events involving genetically modified food make it at the eye of the storm. Some people concern about potentially adverse implications for the consumer's body, environment, next generation and the future. One reason is that there are no sufficient evidences available at present to prove that genetically modified foods in food supply are safe. In other words, scientists, companies and government have responsibilities to prove the safety of genetically modified food to consumers, such as health issues, environment issues and so on. What's more, consumers have rights to know what they eat and to make freely choices about whether or not to buy genetically modified food in the market. Consumer's attitudes towards genetically modified food should be an important determinant for the production of genetically modified foods in the future.

This paper involves some relevant issues referring to genetically modified food in the United States and China. The main purpose of this research aims to describe consumers' attitudes towards genetically modified food in this two countries. Because of the differences of the developmental degrees and situations on transgenic technology in America and Chian. Thus consumers' attitudes toward transgenic technology and genetically modified food are very different.

This essay will be divided four parts. Firstly, i will examine the relevant backgrounds about transgenic technology and genetically modified food. Secondly, i will generally review American consumers' attitudes towards genetically modified food in recent years. Thirdly, Chinese consumers' attitudes towards genetically modified food will be given. Finally, there are conclusion and discussion involving ethical debate on genetically modified food, followed by the related research.

\section{Method}

This paper adopts qualitative methodology. There are a great number of quantitative papers referring to American and Chinese consumers' attitudes towards genetically modified food, in which researchers typically use quantitative method. That is to say, relevant questionnaire questions was designed and distributed to consumers randomly. Then, through collecting and analyzing these questionnaires, results were revealed. What $\mathrm{i}$ will do is to analyze relevant papers, reports and other materials. Then, results will be disclosed. The following is a review on consumers' attitudes towards genetically modified food in the United States and China.

\section{American Consumer's Attitude towards Genetically Modified Food}

Through relevant materials, we can find that commercial sale of genetically modified crops began in 1994 when Calgene first marketed its Flavr Savr delayed ripening tomato. Then, in 1995, the following transgenic crops received marketing approval in America, including bacillus thuringiensis corn, cotton resistant to the herbicide bromoxynil (Calgene), soybeans resistant to the herbicide glyphosate (Monsanto), Bt potatoes (Monsanto), Bt cotton (Monsanto), virus-resistant squash (Monsanto-Asgrow). In addition, scientists invented a new rice containing more nutrient value named golden rice in 2010. Until 2011, approximately twenty-five genetically modified crops had received regulatory approval to be grown commercially. In 2013 , about $85 \%$ of corn, $91 \%$ of soybeans, and $88 \%$ of cotton produced in the United States are genetically modified food. Most genetically modified foods have primarily focused on cash crops in high demand such as, canola, cotton, seed oil, soybean and corn which have been engineered for resistance to pathogens, herbicides or better nutrient profiles. Bedsides genetically modified crops, scientist have cultivated new species through transgenic technology. So far, genetically modified rabbits and chicks have appeared.

Over the past decade, a number of genetically genetically modified food have been commercially produced and exhibited in the markets in the United States. Up to now, almost three-forths of the total crop area devoted to genetically modified crops in the USA. Because of worshiping science and technology, Americans create thousands of new inventions in the history, which make the United States become a leader in the world. At the same time, they have thought of themselves as both a more democratic and scientific culture and they have a special mission for human development and improvement in the global. Such a technological optimism is supported and worshiped in the United States.

We have described the development situation of genetically modified food in the United States above. So, what are American consumers' attitudes towards genetically modified food which is closely related to their lives every day? Through relevant data, it can be found that Americans consumers hold a mixed attitudes towards genetically modified food. Pierre Ganiere et al (2006) pointed that $66 \%$ of the population surveyed supported genetically 
modified food. Yet, they also showed that if genetically modified plants and non-genetically modified plants were similar, such as the same price and characteristics, the majority of respondents favored non-genetically modified food over genetically modified food in the market. Anderson et al (2003) also found that $34 \%$ of Americans consumers indicated that they believed genetically modified food were safe and $29 \%$ thought it unsafe. Hossain et al (2004) considered that consumers in the United States were very optimistic about possible benefits of genetically modified food. But, he also pointed that there might be some risks brought by using and eating of genetically modified food concerning with people's health and environmental risks. It seems that most Americans consumers supported genetically modified food at the beginning.

However, some materials showed that some American consumers oppose genetically modified food. A few scholars pointed that individual behaviors of consumers were driven by risk perception or beliefs about risks rather than the technical risks estimates provided by some scientists and experts. (Frewer et al., 1998) So, consumers' attitudes towards genetically modified food were based on perception risks factor. Onyango (2004) stated that American consumers associated more negative than positive attitude to agro-biotechnology because of perception risk. In addition, recently, some researchers pointed that potential risks and benefits of genetically modified food had been raised and debate among consumers. (Chenyuan Yue et al., 2014) Moreover, they also found that genetically modified food were generally not all favored by consumers in America. If we analyze reasons behind the opposition, it might involve people's previous knowledge, perception risk and safety towards genetically modified technology. Particularly, recent evidences illustrate that the United States consumers have a strong negative preference for genetically modified food.

Among the mixed attitudes involving American consumers' attitudes genetically modified, an important issue about genetically modified food is labeling. A poll conducted by American Consumer Reports National Research Center reveals that $95 \%$ the American consumers agree that food products made from genetically modified crops and animals should be labeled (Business Information, 2009). The US Consumers Union is calling for mandatory safety checks before any genetically modified food is to be sold in the markets. Some parties have proposed labeling food products containing genetically modified material or products in supply chains. For labeling has a particular function to those who believe that consumers will choose to purchase or not to purchase genetically modified food based on these labeling information as a market-base alternative. In fact, labeling might result wholly from voluntary decisions by companies which offer such information to consumers. Through examining New Jersey Consumers' Attitudes Toward Genetically Modified Food Products, Montclair State Researcher find that genetically modified food labeling would help consumers make more fully informed purchasing decisions. Feldman (2014) showed that the most dominating force in the market is the consumer and consumer preferences will make a great impact on industry. Thus, all consumers need to know what is in their food. (Vecchione., 2014) So labeling on genetically modified food would give them more choice and help them to make more informed purchasing behaviors based on their feelings and judgment towards genetically modified food. Besides, there is another issue concerning genetically modified animal. That is to say, consumers in America are overwhelmingly uncomfortable with animal cloning. Anderson et al (2003) stated that $61 \%$ of Americans were opposed animal cloning.

The above represents most American consumer's attitudes towards genetically modified food. In a short, we can infer that American consumers' attitudes towards genetically modified food are complicate. On the one hand, the majority of consumers in the United States believe the power of technology because of their cultural tradition. On the other hand, they also show worries about the safety of genetically modified food, especially genetically modified animal.

\section{Chinese Consumer's Attitude towards Genetically Modified Food}

We have got an overview about American consumers' attitudes towards genetically modified food above. After this, the following is describing Chinese consumers' attitudes towards genetically modified food. However, the opinions of Chinese consumers towards genetically modified food are very different from American consumers.

In 2014, Tencent in China made an internet survey about whether consumers supported genetically modified food or not. The result showed that about $89 \%$ of voters opposed and suspected the safety of genetically modified food. Another investigation made by some experts showed that 55\% Chinese urban consumers worried the safety of genetically modified food, especially to human being's health (Yuanyuan Dong et al., 2014). Another survey also found that most Chinese people preferred traditional food to genetically modified food when they faced these two different kinds of food in markets (Yue Ma, 2014). Besides, some news enhance Chinese consumers' worries to genetically modified food. According a report named Annual Report of Chinese Tumor from Heilong Jang Soybean 
Association in 2012 showed that the consumers who ate genetically modified food were more susceptible to cancers, infertility disease than those ate traditional food. The report also pointed out that there were about 3.5 million new cases of cancers in China adding 2.5 million died of tumor each year and predicated that one reasons causing so many cancers cases in China probably had do to with the consumption of genetically modified food. For example, in the report it showed that some regions, such as, Gansu province, Qinghai province, Henan province, Jiangsu Province, Fujian province, Guangdong province, were the main consumption areas of genetically modified soyean, while these areas were also the tumor cases of concentrated areas as well. By contrary, other regions, for example, the situations of cancer tumor cases in Heilong Jang province, Liaoning province, Shandong province, Guizhou province were less tumors cases than the above provinces. One reason is that these provinces are not the main the consumption of genetically modified soybean.

Compared with the American culture tradition worshiping science and technology, Chinese people are deeply influenced by traditional culture. For example, in Chinese medical science and cooking culture, this is a saying that a special food can affect a certain function of body. That is to say, if one eats the hearts of animals, his or her heart will be enhanced and strengthened. If one eats the brains of animals, his or her brain will become more brilliant. In contrast, if people eat unhealthy or unnatural food, they think that these food will weaken and harm their bodies. For Chinese consumers, transgenic technology introduces foreign genes into the genome of a target organism, which changes the genetic materials of food. As a result, Chinese consumers consider that this procedure is contrary to the laws of nature. Moreover, some consumers also fear that these unnatural materials may cause bodies' heteromorphosis because of the seeds losing progenitive function and being sterile. So, some Chinese consumers think that genetically modified food which cannot reproduce next generation will weaken men's potential generandi.

Besides the above health risk towards genetically modified food which Chinese consumers are worried, there are other reasons about why so many Chinese consumers oppose genetically modified food, such as economic issue, environment issue and labeling.

First, economic issue is another important reason about why most Chinese consumers disapprove genetically modified food. Corporations researching genetically modified food are to pursue profits. That is to say, monetary interest is a very significant force driving factor for firms to research genetically modified food. Thus, it can be inferred that the main purpose of some biotech companies investing and researching genetically modified food is to monopolize the markets of seed and control one country's agriculture in the further in order to get more interests regardless of other problems. As Xinzhi Mao (2011) stated that transgenic technology and plants were monopolized by foreign companies and these big transnational corporations controlled the seed markets through technology advantages. Some biotech firms may deprive farmers' rights of conserving and changing seeds through technology monopoly and compel farmers to purchase seeds every year from their companies. As a result, the consumer will be worried that they may lose rights of choice freely in the markets. "the agrichemical farm industry seeks to control our food system by keeping us in the dark as to what, exactly, is in our food and being released into our environment." (Tiffany., 2012) In short, most Chinese consumers suspect that the power which will change seed market is not the force of technology, but capital.

In addition, environmental issue is another reason why Chinese consumers oppose the prevalence of genetically modified food. Chinese consumers are worried that transgenic plants may damage regional ecology. Yet, local persons have to undertake the risks of losing good environment. Many data show that transgenic plants might be hazards to the environment. For example, Some scholars in China consider that genetically modified plants may affect soil surroundings. (Jianwu Wang et, al., 2002) The ecological consequences of gene flow from pollination may be deleterious effects for soil ecology, microflora, underground water tables and loss of biodiversity. Compared with the spontaneous evolution, the rivalrousness of genetically modified food is stronger. Because those species who are implanted insect-resistance gene are easier to defense the attach of pests. If things continue in this way, transgenic plants will replace the traditional species. As a result, some areal species will extinct. Another important reality is that the agricultural foundation of China is relative weak and agricultural ecology is complex and stable. Without ample scientific research, genetically modified crops may bring a great influence on Chinese agrobiological environment. It needed more and deeper investigation before popularizing any genetically modified plants. (Zhen Zhu, 2011) Once ecosystem is damaged, it need more time to renew. Or it may never be recovered.

Finally, labeling on genetically modified food issue is similar with America. Sometimes, it can be found that few food is labeled containing genetically modified organism soya bean oil ingredient when Chinese consumers know less about genetically modified. But this labeling is replaced by vague ingredient description in 2014 because of most consumers' opposition towards genetically modified food. One reasonable explanation is that businessman may want 
to keep good sales and avoid bad impact from the debate of genetically modified food. However, this situation is a little different from the United States. That is to say, whether genetically modified food should be labeled or not has not caused hot debate among Chinese consumers. For example, America has passed Proposition 37 which is written with broad input from food groups, industry, science, legal and health experts in order to help consumers to make informed choices about the food what they eat. Besides, California Right to Know Genetically Engineered Food Act also requires clear labeling to let consumers know whether foods contain genetically modified. At the same time, New Jersey bill is proposed and required by consumers. But, there is few news and movement about genetically modified food labeling in China.

In brief, Chinese consumers' attitudes towards genetically modified food are different from American consumers. Most people oppose genetically modified food in China and the reasons are complicated and multiple. Chinese consumers are more inclined to traditional culture and cooking than genetically modified food and they are worried the safety of genetically modified food, including health issue, economic issue environmental issue and so on. Yet, they have weaker concept of right American consumers about how to solve the current situation on genetically modified food, for example, labeling.

\section{Discussions and Conclusions}

We have revealed the differences between American consumers and Chinese consumers' attitudes towards genetically modified food the above. It can be seen that although the United States consumers are more favorable inclined to genetically modified food than Chinese consumers, consumers in these two countries have the same, such as health risk, environmental risk brought transgenic technology and genetically modified crops. Because consequences of using genetically modified food are still uncertain and scientific consensus over the risk associated with it has not emerged. Scientific researches do not provide answers to the above issues. It is only a method to validate or invalidate hypotheses about nature phenomena. Meanwhile, these researches consider less other issues. What's more, some scientists optimistically claim that they could discover the language in which God create human life through gene technology. However, what they said fears consumers. For example, Biologist Séralini (2012) published a research report for two years study and said that those mice who were fed genetically modified crop NK603 had shorter life than normal mice. The former owned presence of tumors with higher probability.

In addition, in the produces of researching genetically modified food, ethical thinking needs to be considered. As Shanling Ye (2014) showed that although transgenic technology is a representation of high technology, it exists the characteristic of uncertainty. Because many potential negative problems deriving from technology may be found in a few decades. For example, the history of DDT as a good example can explain this view explicitly. DDT was thought the most efficient insecticide previously. But after decades of using it, people just discovered the damage of this new synthetic chemicals to the health of human beings, animals, environment and so on. This case also apply for the thinking of practicing of genetically modified food in the future. Some modern technologies contain uncertainties, which may increase the risks in the future. Genetically modified food deriving from transgenic technology also adds up to the risks. Moreover, these risks not only involve current human being's health, species diversities and ecological environment, but also affect the next generation, even future generations after the safety of genetically modified food can be guaranteed absolutely. Thus, the biggest question of genetically modified food is that its ultimate consequences are not clear and it may need several generations' test to prove the safety of it. Even some consequences may be irreversible.

Compared with America and China, European Union is more cautious and stricter towards genetically modified food. European Union adopts precautionary attitudes towards the production and import of genetically modified food, takes strictly supervision on the marketing of genetically modified food and requires identification of genetically modified food. In short, European Union's regulation about genetically modified food is influenced by the precautionary principle. The precautionary principle can be defined that in areas where science is limited or outcomes are unpredictable, regulatory authorities are justified in taking action to avoid possible negative outcome. Precautionary principle comes from Rio Declaration on Environment and Development in 1992. In this report, it can be seen that "the precautionary approach shall be widely applied by States according to their capabilities. Where there are threats of serious or irreversible damage, lack of full scientific certainty shall not be used as a reason for postponing cost-effective measures to prevent environmental degradation." Thus, if genetically modified food is new species, policy makers are obliged not to approve products for release until they are shown not to pose a danger to human being and environment. Besides precautionary principle showed above, another ethical principle non-maleficence should be considered in the food supply. As Shaopong Gan (2014) said that risk issue decided what 
we behavior is not to harm, especially the benefits of further generations. We should guarantee the next and further generation should have the same choice rights like us.

Finally, governments and firms need to respond to calls of the consumers to label on genetically modified food and allow consumers to choose them freely in the market. It is a fundamental right of consumers to know the content of their food. It is noted that the significant public opposition to genetically modified food shows that the industry should adopt honest and appropriate manners to avoid more contradiction. Besides, consumers have right to call for government to establish national regulatory systems to insure genetically modified food safety and protect the health of consumers and environment.

\section{The Related Research}

We have discussed the different and same situation appeared in the United States and China. In summary, transgenic technology and genetically modified food are controversial and consumers towards it are complex. The debate on genetically modified food involves consumers, farmers, biotechnology companies, governmental regulators, non-governmental organizations, scientists socialists, philosophers and so on. Although consumers can not stop the development of genetically modified food, consumers have rights to know the content of the food which they eat every day.

Thus, according to consumers' attitudes towards genetically modified food in these two countries, some relevant issue-related tasks should be done further. First, for scientists, they should research deeply the transgenic technology and should take more experiments before a bulk of production for consumers and transplanting genetically modified species to the wild. Second, for some companies investing much money on research of genetically modified food, they should consider more benefits of consumers, environment, further generations, morality factors and corporate social responsibility except shareholders and companies. Third, for the government, National Food Administration should tested the security of using genetically modified food. Before genetically modified food can be certified healthy and safety to environment, it had better not to spread planting. Finally, the most important issue it to label on the genetically modified food. Government and firms should give consumers rights to choose freely in the market and consumers also have rights to know what they eat.

\section{Acknowledgments}

There are many people to whom i owe gratitude for their support during the course of writing this paper. Firstly, I wish to thank my teachers who works in the Graduate School of Chinese Academy of Social Science, in which i improve my abilities of learning and writing. Secondly, i give my sincere thanks to my classmates because of their helps. Finally, i give my sincere thanks to all people who support and encourage me during the writing of paper.

\section{References}

Anderson, K., \& Jackson, L. A. (2003). Why are US and EU policies toward GMOs so different? AgBioForum, 6(3), 95-100.

Carl, C. K., \& Gallegos, L. K. (2006). Safety of Genetically Engineered Food. Agricultural biotechnology in California series, 8180(12), 1-5.

Chengyan Yue, Shuoli Zhao, \& Jennifer Kuzma1. (2014). Heterogeneous Consumer Prefere for Nanotechnology and Genetic-modification Technology Food Products. Journal of Agricultural Economics, 65(1), 1-21.

Dona, A., \& Arvanitoyannis, I. S. (2009). Health Risks of Genetically Modified food. Critical Reviews in Food Science and Nutrition, 49(2), 164-175.

$\mathrm{Fu}$ Bi. (2014). The Right and Wrong of Genetically Modified Food. Economic Relation and Trade. http//dx.oi.org/10.3969/j.issn.1003-5559.2014.09.026

Jianwu Wang, Yuan jiao Feng, \& Shiming Luo. (2002). Effects of Transgenic Crops on Soil Ecosystem. Chinese journal of applied ecology, 13(4), 491-494.

Global Scan. (2013, September 10). European Union's precautional attitudes towards genetically modified food, Economic Herald, 44-47.

Hossain, F., \& Onyango, B. (2004). Product attributes and consumer acceptance of nutritionally enhanced genetically 
modified foods. International Journal of Consumer Studies, 28(3), 255-267.

Ling Zhang, Jie Wang, \& Jinan Zhang. (2006). Consumer welfare and GM food labeling: A simulation using an adjusted Kumaraswamy distribution Technophobia about Genetically Modified Foods and Strategy. Journal of Dialectics of Nature, 166(6), 57-61.

Li Zhao, Haiying Gu, Chengyan Yue, \& David Ahlstrom. (2013). Consumer welfare and GM food labeling: A simulation using an adjusted Kumaraswamy distribution. Food Policy. Retrieved from http://www.sciencedirect.com/science/article/pii/S0306919213000729

Montserrat Costa-Font., Jose M. Gil., \& W. Bruce Traill. (2008). Consumer acceptance, valuation of and attitudes towards genetically modified food: Review and implications for food policy. Food Policy. Retrieved from http://www.researchgate.net/publication/4793666_Consumer_acceptance_valuation_of_and_attitudes_towards_ genetically_modified_food_Review_and_implications_for_food_policy

Onyango, B. (2004). Consumer acceptance of genetically modified foods: the role of product benefits and perceived risks. Journal of Food Distribution Research, 35(1), 154-161.

Pierre Ganiere., Wen S. Chern., David Hahn, \& (2006). A Continuum of Consumer Attitudes toward Genetically Modified Foods in the United States. Journal of Agricultural and Resource Economics, 3l(1), 129-149.

Pusztai, A., \& Bardocz, S. (2011). Potential Health Effects of food Derived from Genetically Modified Plants: What Are the Issues? Malaysia: Third World Network.

Shaoping Gan. (2014). Risk Ethic Exceeding Responsibity Ethic. Philosophical Researches, 714(9), 87-94.

Zhen Zhu. (2011). Advantages and Disadvantages Analysis of Genetically Modified Food to Environment, Current Biotechnology. http//dx.oi.org/10.3969/10.3969/j.issn.2095-2341. 2011.04.01

Shanling Ye. (2014). Ethical Analysis of Safeties of Genetically Modified Food. Studies in Dialectics of Nature, 30(5), 37-42.

Xinzhi Mao. (2011). On the Industrialization of GM Rice in China: Dilemmas and Wayout. Journal of Nanjing Agricultural University (Social Sciences Edition), 603(3), 124-131.

Chengyan Yue, Shuoli Zhao, \& Jennifer Kuzma. (2014). Heterogeneous Consumer Preferences for Nanotechnology and Genetic-modification Technology in Food Products. Journal of Agricultural Economics. http//dx.oi.org/10.3969/10.1111/1477-9552.12090

Yuanyuan Dong, Zhenhong Qi, Dongmin Zhang, \& Xuanyi Feng. (2014). Effect of Perceived risk GMF on Consumers' Purchase Intention: Based on A Survey Conducted in Wuhan. Journal of China Agricultural University, 19(3), 27-33.

Yue Ma. (2014). Reasons Analysis of Chinese Urban Consumers Opposing Genetically Modified Food-An Overview. Studies of in Asian Social Science, 4(2), 11-15. 